\title{
Evidence That RNA Silencing-Mediated Resistance to Beet necrotic yellow vein virus Is Less Effective in Roots Than in Leaves
}

\author{
Ida Bagus Andika, Hideki Kondo, and Tetsuo Tamada \\ Research Institute for Bioresources, Okayama University, Kurashiki, Okayama 710-0046, Japan
}

Submitted 6 August 2004. Accepted 2 November 2004.

\begin{abstract}
In plants, RNA silencing is part of a defense mechanism against virus infection but there is little information as to whether RNA silencing-mediated resistance functions similarly in roots and leaves. We have obtained transgenic Nicotiana benthamiana plants encoding the coat protein readthrough domain open reading frame $(54 \mathrm{kDa})$ of Beet necrotic yellow vein virus (BNYVV), which either showed a highly resistant or a recovery phenotype following foliar rub-inoculation with BNYVV. These phenotypes were associated with an RNA silencing mechanism. Roots of the resistant plants that were immune to foliar rub-inoculation with BNYVV could be infected by viruliferous zoospores of the vector fungus Polymyxa betae, although virus multiplication was greatly limited. In addition, virus titer was reduced in symptomless leaves of the plants showing the recovery phenotype, but it was high in roots of the same plants. Compared with leaves of silenced plants, higher levels of transgene mRNAs and lower levels of transgene-derived small interfering RNAs (siRNAs) accumulated in roots. Similarly, in nontransgenic plants inoculated with BNYVV, accumulation level of viral RNA-derived siRNAs in roots was lower than in leaves. These results indicate that the RNA silencing-mediated resistance to $B N Y V V$ is less effective in roots than in leaves.
\end{abstract}

\section{Additional keyword: Benyvirus.}

RNA silencing is a sequence-specific RNA degradation mechanism that occurs in a broad range of eukaryotic organisms, including fungi, plants, and animals. RNA silencing is induced by double-stranded (ds)RNAs or structured singlestranded (ss)RNAs, which are processed into 21- to 25-nucleotide (nt) small interfering (si)RNAs by RNase III-like enzymes (Bernstein et al. 2001; Elbashir et al. 2001; Hamilton and Baulcombe 1999). The siRNAs are incorporated into the RNAinduced silencing complex (RISC), in which they serve as guides to target complementary RNAs for destruction (Hammond et al. 2000; Tang et al. 2003). In plants, RNA silencing generates mobile signals with sequence-specific information that spread between cells via plasmodesmata and long distances via phloem (Mlotshwa et al. 2002; Palauqui et al. 1997; Voinnet et al. 1998). This signal most likely has nucleic acid components, because it mediates a nucleotide sequence-specific effect (Mlotshwa et al. 2002).

Corresponding author: T. Tamada; Telephone:+81-86-434-1229; Fax:+8186-434-1249; E-mail: ttamada@ rib.okayama-u.ac.jp
It has been accepted that the transgenic plant harboring a viral RNA sequence may show high levels of virus-specific resistance that was mediated by RNA silencing (Baulcombe 1996; Matzke et al. 2001; Vance and Vaucheret 2001; Voinnet 2001; Waterhouse et al. 2001). Most of the three common viral genes (or sequences), coat protein, replicase, and movement protein, have been successfully employed for generation of virus-resistant plants. However, there are no clear rules to indicate which genes or sequences will be most effective to induce resistance. In some cases, transgenic plants initially develop a systemic viral infection but resistance is later induced in developing leaves that appear to be virus free and resistant to new infection with the same virus. Such a recovery resistance is also known to be mediated by silencing of the transgene induced by virus infection (Dougherty et al. 1994; Lindbo et al. 1993). Resistance responses have been mostly demonstrated on the basis of phenotypes appearing in the aerial parts of the plant in which the virus was mechanically inoculated to leaves. However, there has been little information as to how a RNA silencing mechanism involved in virus resistance operates in the root systems, although the roots play an important role in the virus life cycle (Hull 2002). In fact, many soilborne viruses have been identified in recent years, most of which are directly transmitted to roots of plants by soil-inhabiting organisms such as fungi or nematodes (Verchot-Lubicz 2003). Several viruses are agriculturally important not only because they cause a yield loss in many crops but also because they are difficult to control. Therefore, RNA silencing-mediated resistance (includeing pathogen-derived resistance) has been expected as a means to control soilborne viruses (Verchot-Lubicz 2003).

Beet necrotic yellow vein virus (BNYVV, genus Benyvirus) is transmitted by the soil-inhabiting plasmodiophoromycete fungus Polymyxa betae and causes the economically important rhizomania disease of sugar beet (Tamada 1999). BNYVV has rigid rod-shaped virions and a multipartite plus-strand RNA genome, which consists generally of four or, in some isolates, five distinct RNA species, referred to as RNA1 to RNA5 (Tamada 1999). RNA1 and RNA2 encode "house-keeping" genes involved in viral RNA replication, assembly, and cell-tocell movement. RNA3, RNA4, and RNA5 are associated with vector-mediated infection and disease development in sugar beet roots. RNA2 contains six genes (Fig. 1A), including a triple gene block involved in cell-to-cell movement (Gilmer et al. 1992) and a 3' proximal gene encoding P14, which may function as a suppressor of RNA silencing (Dunoyer et al. 2002). The 5' proximal half of RNA2 carries the genes for the viral structural proteins. The major capsid protein $(\mathrm{CP})(21 \mathrm{kDa})$ is encoded by the $5^{\prime}$ proximal open reading frame (ORF). This cistron terminates with a single amber termination codon that 
is suppressed about $10 \%$ of the time, to produce a fusion between the major $\mathrm{CP}$ and the sequence encoded by the adjacent in-frame ORF, referred to as the 54-kDa readthrough domain (RTD) (Bouzoubaa et al. 1986) (Fig. 1A). The resulting 75$\mathrm{kDa}$ protein $(\mathrm{P} 75)$ is a minor component of virions and is located at an extremity of the viral particles (Haeberle et al. 1994). P75 is required for efficient virus assembly (Schmitt et al. 1992) and for virus transmission by $P$. betae (Tamada and Kusume 1991; Tamada et al. 1996). A CP readthrough protein is also encoded by the genomes of other plasmodiophoromycete fungus-transmitted rod-shaped viruses, such as the furoviruses and pomoviruses (Hull 2002). In the case of fungustransmitted pecluviruses, an apparent homolog of the RTD is expressed independently of the CP by leaky scanning (Herzog et al. 1995).

In this study, we have transformed Nicotiana benthamiana plants with the CP gene or the gene for the 54-kDa RTD ORF of BNYVV. Only 54-kDa RTD-ORF transgenic plants showed frequent high resistance and recovery phenotypes following foliar rub-inoculation with BNYVV. Our molecular analysis shows that high resistance is mediated by transgene-induced RNA silencing and that recovery is mediated by silencing of the transgene induced by virus infection. We compared the differences of RNA degradation in leaves and roots, using these transgenic and nontransgenic plants. The results show that the RNA silencing-mediated resistance is less effective in roots than in leaves.

\section{RESULTS}

Characterization of transgenic $N$. benthamiana lines.

The BNYVV minor CP P75 is a fusion protein between the major 21-kDa CP (encoded by ORF1 on RNA2) and the 54kDa RTD (encoded by ORF2 on RNA2) (Fig. 1A). In this study, transgenic $N$. benthamiana plants expressing the $\mathrm{CP}$ gene or the 54-kDa RTD ORF were produced by Agrobacterium tumefaciens-mediated transformation. In the T-DNA, the leaky termination codon (TAG) separating ORF1 and ORF2 was replaced by a start codon (ATG) so that only 54-kDa protein would be synthesized (Fig. 1A). The cDNA sequence was placed under transcriptional control of a 35S Cauliflower mosaic virus (CaMV) promoter and a nopaline synthase (NOS) terminator sequence (Fig. 1A). Transgenic N. benthamiana plants expressing a synthetic jellyfish green fluorescent protein gene [sGFP(S65T)] (Chiu et al. 1996) were produced as a control. Transformed and regenerated plants of $N$. benthamiana were self-pollinated, and $\mathrm{T}_{1}$ progeny from each line were first screened for resistance to kanamycin. The presence of inserted genes in the transgenic lines was subsequently confirmed by the polymerase chain reaction (PCR). Twenty 54-kDa RTDORF transgenic lines, $19 \mathrm{CP}$ transgenic lines, and 16 sGFP transgenic lines were selected and used for the BNYVV resistance tests. The transgenic $N$. benthamiana plants were morphologically undistinguishable from nontransgenic plants.

The $\mathrm{T}_{1}$ progeny of each transgenic plant line were screened by foliar rub-inoculation with BNYVV. Inoculation of nontransgenic $N$. benthamiana plants typically resulted in a downward curling and stunting on systemically infected leaves at 12 to 14 days postinoculation (dpi), followed by faint and then severe mosaic symptoms (Fig. 2). The 54-kDa RTD-ORF transgenic plants that were infected with BNYVV were divided into three phenotypes of symptom development. The first class of transgenic plants displayed a high resistance phenotype (referred to as HR), in which no systemic symptoms developed (Fig. 2). The second class displayed a recovery phenotype (referred to as RC), in which systemic symptoms appeared within two weeks after inoculation (Fig. 2) but, three to four weeks later, the newly developing leaves were symptomless (Fig. 2) and were resistant to rub-inoculation with BNYVV. The third class was a susceptible phenotype, in which symptoms were similar to those of nontransgenic plants. Out of $2054-\mathrm{kDa}$

A

BNYVV RNA2

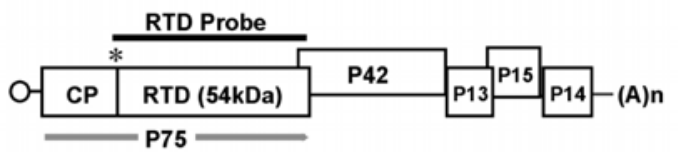

pBI-CP
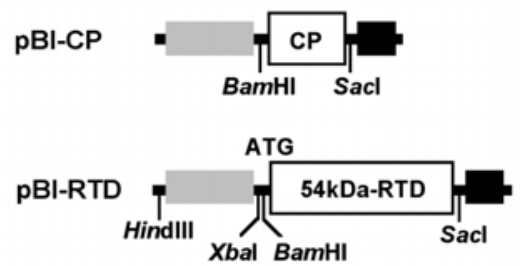

B

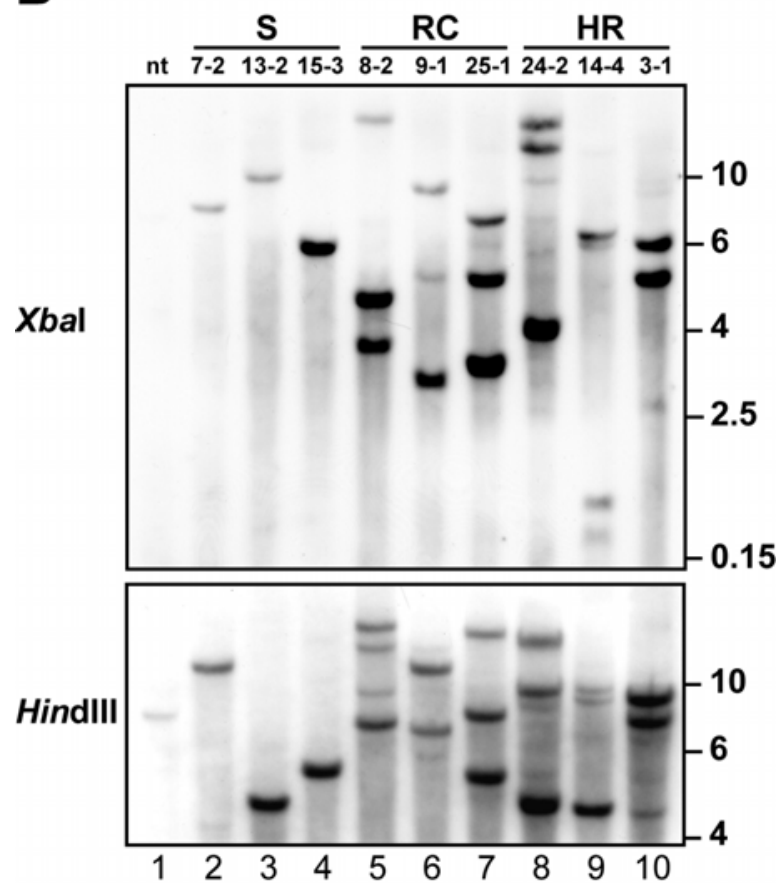

Fig. 1. A, Schematic map of Beet necrotic yellow vein virus (BNYVV) RNA2 and schematic representation of constructs used for plant transformation. BNYVV RNA2 has a cap structure (open circle) at its 5'terminus and is polyadenylated after the 3 ' end (A)n. RNA2 contains six open reading frames (ORFs, rectangle). The coat protein $(\mathrm{CP})$ cistron is separated from a long in-phase ORF (54-kDa readthrough domain, RTD) by a single amber termination codon (star) that is suppressed about $10 \%$ of the time to produce a $75-\mathrm{kDa}$ fusion protein (P75). For the 54-kDa RTDORF transgene, that amber stop codon (TAG) was replaced by a start codon (ATG). The CP gene and the 54-kDa RTD ORF were inserted between the $35 \mathrm{~S}$ Cauliflower mosaic virus promoter (gray rectangle) and nopaline synthase terminator (black rectangle). Restriction enzyme sites are indicated. The location of the RTD probe used in RNA and DNA blottings is indicated above the map of BNYVV RNA2. B, Southern blot analysis of genomic DNA from BNYVV 54-kDa RTD-ORF transgenic plants showing different phenotypes. DNA samples were prepared from leaves of nontransgenic (nt) Nicotiana benthamiana plants, three transgenic susceptible (S) lines, three transgenic recovery (RC) lines, and three transgenic highly resistant (HR) lines. Transgenic plant lines are as indicated at the top of each lane. Genomic DNA $(20 \mu \mathrm{g})$ was digested with $X b a \mathrm{I}$ or HindIII and was hybridized with a digoxigenin-labeled DNA probe specific to a 54-kDa RTD-ORF sequence. Sizes (in kilobase pairs) for DNA makers are shown to the right. 
RTD-ORF transgenic lines tested, six (30\%), nine (45\%), and five $(25 \%)$ lines contained plants showing the HR, RC, and susceptible phenotypes, respectively.

In contrast to the 54-kDa RTD-ORF transgenic plants, 18 out of $19 \mathrm{CP}$ transgenic plant lines showed symptoms that were similar to nontransgenic control plants (data not shown). No recovery phenotypes were observed in these susceptible plants, as mentioned above. Only one line displayed a partial resistance phenotype. In this line, the virus was detected in inoculated leaves and about half of the inoculated plants became systemically infected, but symptom development was delayed compared with nontransgenic plants (data not shown). None of the 16 sGFP transgenic plant lines showed delays in infection or any level of resistance.

Thus, the 54-kDa RTD-ORF transgenic plant lines $\left(\mathrm{T}_{1}\right)$ displayed RC or HR phenotype at high frequency. The $\mathrm{T}_{2}$ progeny from each $T_{1}$ line were again screened for resistance to BNYVV infection. We selected three HR lines (RT24-2, RT14-4, and RT3-1), three RC lines (RT8-2, RT9-1, and RT25-1), and three susceptible lines (RT7-2, RT13-2, and RT15-3) for further molecular analysis. Southern blot analysis was performed to determine the transgene copy number in plants of the transgenic lines $\left(\mathrm{T}_{2}\right)$ showing the three different phenotypes. Genomic DNA was digested with $\mathrm{XbaI}$ and HindIII (Fig. 1A) and was hybridized with the transgene probes. As shown in Figure 1B, two or more copies of the transgene were detected in plants of three RC lines and three HR lines, whereas plants of the three susceptible lines contained single copies.

To examine the level of accumulation of transgene transcript, Northern blot analysis was performed, using total RNA extracted from leaves of transgenic $N$. benthamiana lines showing the three different phenotypes. The results showed that high levels of transgene transcripts were observed in leaves of the three RC lines tested (Fig. 3A, lanes 5 to 7), whereas only trace amounts of transcripts were detected in leaves of the three HR lines (Fig. 3A, lanes 8 to 10) or the three susceptible lines (Fig. 3A, lanes 2 to 4). Next, we examined the levels of transcript accumulation in the recovered, symptomless leaves of RC plants at 30 dpi. The transgene mRNAs were reduced to undetectable levels in the recovered leaves of the three plant lines following virus infection (Fig. 3B, lanes 5 to 7), as compared with high levels of transcripts in leaves of the same RC plant lines before virus infection (Fig. 3B, lanes 2 to 4). Thus, we consistently observed a high level of 54-kDa RTD-ORF mRNA accumulation only in the RC plant lines, but a strong reduction of transgene mRNA levels occurred in the recovered, symptomless leaves of the plants following BNYVV infection.

It is accepted that the accumulation of siRNAs originating from the target sequence is diagnostic of RNA silencing (Hamilton and Baulcombe 1999; Llave et al. 2002). We have examined accumulation levels of siRNAs from leaves of the transgenic plants, using an antisense RNA probe specific for the 54-kDa RTD-ORF sequence. Transgene-derived siRNAs were detected in RNA extracts from leaves of the two HR lines (RT24-2 and RT14-4) (Fig. 3C, lanes 5 and 6) and from the recovered leaves of the two RC lines (RT8-2 and RT9-1) after BNYVV infection (Fig. 3C, lanes 3 and 4) but not in RNA extracts from leaves of the same RC plant lines before BNYVV infection (Fig. 3C, lanes 1 and 2) or susceptible plant lines (RT7-2 and RT13-2) (data not shown). From these results, we conclude that the high resistance in BNYVV 54-kDa RTDORF transgenic plants is mediated by RNA silencing, whereas the recovery is mediated by silencing of the transgene induced by virus infection.

\section{BNYVV infection in roots}

of transgenic $H R$ plants by fungal inoculation.

The natural vector of BNYVV is the soil-inhabiting fungus $P$. betae, which is a parasite on roots of sugar beet plants (Tamada 1999). We have found that viruliferous zoospores of $P$. betae are also able to transmit BNYVV to roots of $N$. ben-
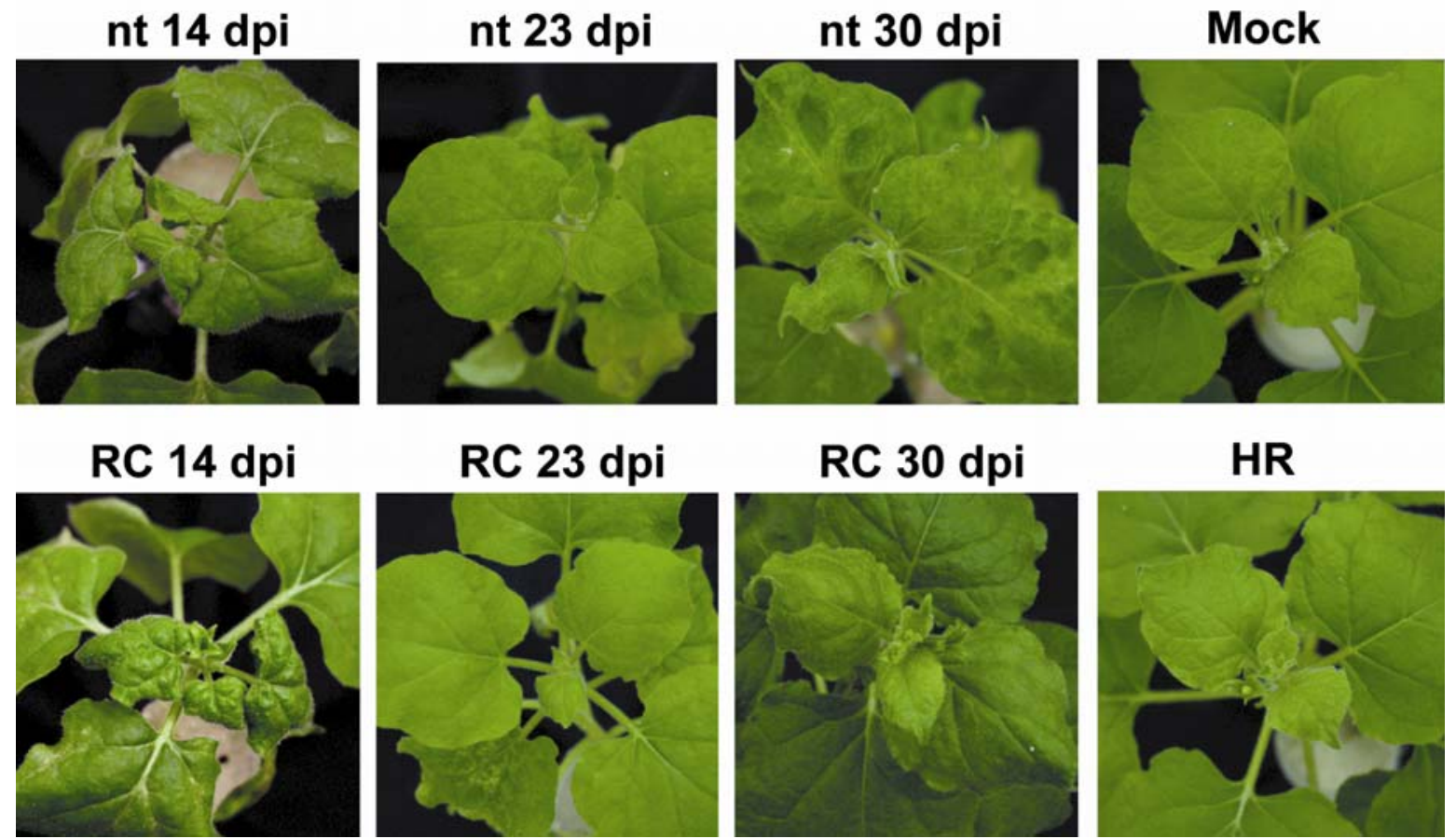

Fig. 2. Symptoms of Beet necrotic yellow vein virus (BNYVV)-O11 in Nicotiana benthamiana plants by foliar rub-inoculation. The inoculated plants are either nontransgenic (nt) plants or 54-kDa readthrough domain-open reading frame (RTD-ORF) transgenic recovery (RC) plants, both of which show similar leaf curling symptoms at 14 days postinoculation (dpi). In nt plants, systemic symptoms are faint mosaic at 23 dpi and severe mosaic with slight leaf distortion at 30 dpi. In RC plants, upper leaves are symptomless at 23 dpi and completely recovered at 30 dpi. A 54-kDa RTD-ORF transgenic highly resistant (HR) plant and a mock-inoculated nt plant (Mock) are included. 
thamiana plants, although resting spores of the fungus are not formed in this host (T. Tamada, unpublished data). In nontransgenic $N$. benthamiana plants inoculated with viruliferous zoospores of $P$. betae, systemic symptoms were observed three to four weeks after inoculation, which was a delay of two weeks compared with foliar rub-inoculation. All the progeny (>50 plants) of the RT24-2 line (HR-phenotype) were completely resistant to foliar rub-inoculation with BNYVV (virus was not detected in inoculated leaves), and therefore, we have examined whether this transgenic plant line has resistance to BNYVV by fungus-inoculation. At 12, 18, and 24 days after zoospore inoculation, virus infection of the roots was assessed by enzyme-linked immunosorbent assay (ELISA). As shown in Figure 4A, viruliferous zoospores of $P$. betae were able to efficiently transmit BNYVV to roots of nontransgenic $N$. benthamiana plants, and the virus titer in the infected roots could become very high. In contrast, although viruliferous $P$. betae was able to infect the roots of the transgenic HR plants, the virus titer was very low compared with nontransgenic plants (Fig. 4A). The levels of virus accumulation differed between individual plants, but they were roughly divided into two groups, one-third of the plants contained relatively high virus levels (mean titer, $13.7 \mu \mathrm{g}$ per $\mathrm{g}$ of tissue) and the other two-thirds showed only a low level of virus accumulation (mean titer, 1.0 $\mu \mathrm{g}$ per $\mathrm{g}$ of tissue). These observations suggest that two different types of resistance, high and moderate, are present in the population of the RT24-2 $\mathrm{T}_{2}$ seedlings, which segregate to give a close fit to a ratio of $3: 1$. It is, therefore, possible that a single independent locus of the transgene integrated on the chromosome may influence the extent of resistance, although the RT24-2 line contains two or more copies of transgene (Fig. $1 \mathrm{~B}$, lane 8). In addition, it was noted that although the virus content approximately doubled in the roots of the nontransgenic plants between 12 and $18 \mathrm{dpi}$, the levels of virus accumulation in roots of the HR plants were not greatly different between these two sampling dates (Fig. 4A). We take these observations to mean that root tissues of the HR plants were initially infected with BNYVV by the fungus but that thereafter virus replication and movement was greatly limited. No differences in virus accumulation were found between transgenic RC (RT8-2) and nontransgenic plants, when inoculated by the fungus (data not shown).

The levels of BNYVV RNA accumulation in roots of the $\mathrm{HR}$ and nontransgenic plants at 20 dpi were also confirmed by Northern blot analysis. Large amounts of viral RNA1 and RNA2 accumulated in roots of the nontransgenic plants (Fig. 4B, lanes 2 to 4 ), whereas lower levels of viral RNAs were detected in roots of the HR plants (Fig. 4B, lanes 5 to 14). Viral RNA accumulation levels differed between individual plants; three out of ten plants tested contained relatively high levels of RNAs (Fig. 4B, lanes 5, 12, and 14), but the levels in the other seven plants were below detection levels by Northern blot analysis (Fig. 4B, lanes 6 to 11 and 13), although they could be detected by reverse transcription (RT)-PCR (data not shown). These data are consistent with the ELISA results described above. Thus, roots of the HR plants that were immune to foliar rub-inoculation could be infected by viruliferous zoospores of the vector fungus $P$. betae, although virus multiplication was greatly limited.

\section{BNYVV infection in leaves and roots}

of transgenic RC plants by foliar rub-inoculation.

To compare the levels of virus accumulation in leaves and roots of transgenic RC (line RT8-2) and nontransgenic N. benthamiana plants by foliar rub-inoculation, we have used a tissue imprinting assay, ELISA, and Northern blot analysis. Leaf samples were collected from the inoculated leaves (position 0), all leaves (positions +1 to +6 ) above the inoculated leaves at $17 \mathrm{dpi}$, and leaves (positions +4 to +10 ) at 28 dpi. Strong signals in tissue imprints were found in inoculated leaves $(0)$ in the RC and nontransgenic plants at $17 \mathrm{dpi}$ but not in leaves at position +1 (Fig. 5A). In other tissues, the staining intensity in tissue imprints (Fig. 5A) in different leaf positions and roots at 17 and 28 dpi paralleled the virus titers as estimated by ELISA (Fig. 5B). Taken together with the two assays, at $17 \mathrm{dpi}$, the virus content was high in the leaves at positions +2 to +4 but was lower in the leaves at positions +5 and +6 (Fig. $5 \mathrm{~A}$ and $\mathrm{B}$ ). At this time point,

A

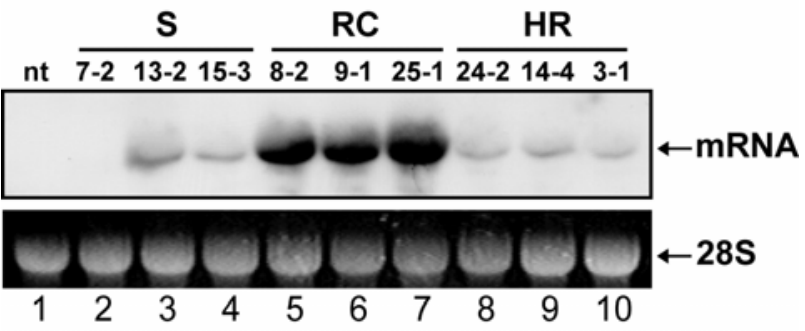

B

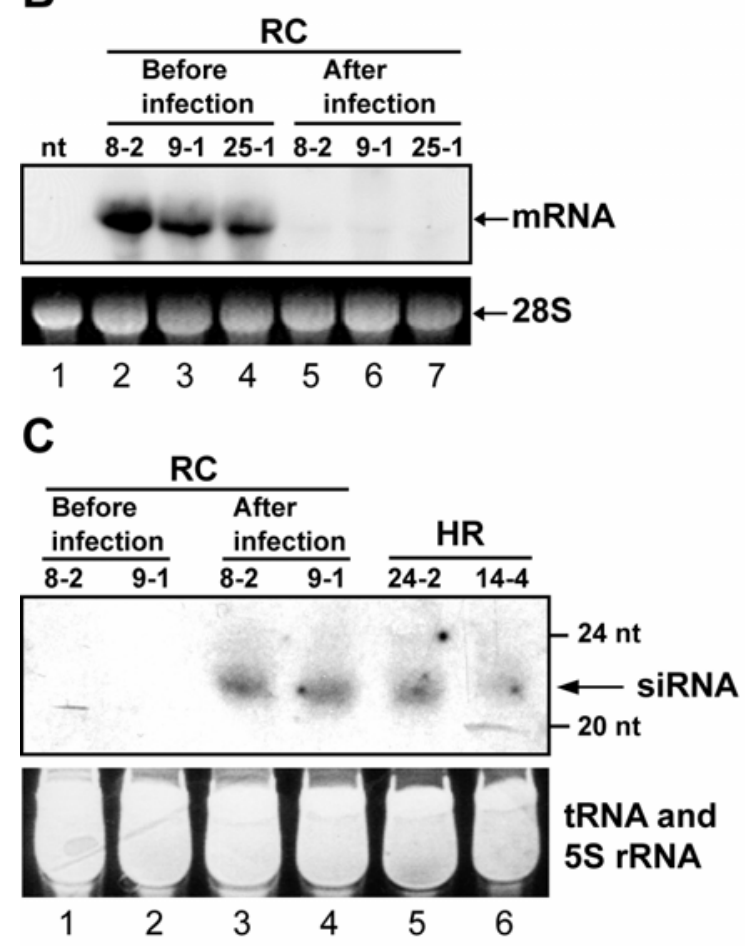

Fig. 3. Northern blot analysis of Beet necrotic yellow vein virus (BNYVV) 54-kDa readthrough domain-open reading frame (RTD-ORF) transgenic Nicotiana benthamiana plant lines showing susceptible (S), recovery (RC), or high resistance (HR) phenotypes. Transgenic plant lines are identified at the top of each lane. RNA samples were prepared from pooled leaves of five plants. A and B, Detection of transgene mRNA in total RNA extracted from leaves of transgenic or nontransgenic (nt) plants. A shows nontransgenic (nt), S, and RC plants before BNYVV infection and HR plants. B shows nt and RC plants before BNYVV inoculation and fully recovered leaves of RC plants after inoculation. Total RNA $(20 \mu \mathrm{g})$ was hybridized with a digoxigenin-labeled DNA probe specific for a 54-kDa RTD-ORF sequence (top). Ethidium bromide-stained 28S rRNA is shown as loading control (bottom). C, Detection of short interfering RNAs (siRNAs) in RNA samples from leaves of $\mathrm{HR}$ and $\mathrm{RC}$ plants before BNYVV infection and from the fully recovered leaves of RC plants after BNYVV infection. A ${ }^{32} \mathrm{P}$-labeled antisense RNA probe specific for a 54kDa RTD-ORF sequence was used for hybridization. The positions for 20and 24-nucleotide DNA oligomers are indicated. Ethidium bromidestained tRNA and 5S rRNA is shown as loading control (bottom). 
the levels of virus accumulation in the RC plants were similar to those in the nontransgenic plants (Fig. 5A and B). At 28 dpi, the virus titers were further decreased in the leaves at positions +4 to +6 from both the $\mathrm{RC}$ and nontransgenic plants (Fig. 5A and B), and the symptoms in leaves +5 and +6 of both the plants were faint mosaic. For the nontransgenic plants, however, the virus titers began to increase in the leaves at positions +7 and above, and the accumulation levels remained at a relatively high level (Fig. 5A and B). These leaves showed severe mosaic symptoms with a slight leaf distortion (Fig. 2). In contrast, the virus titers in the leaves at the same positions $(+7$ to +10$)$ from $\mathrm{RC}$ plants were reduced to very low or undetectable levels (Fig. 5A and B) as leaf positions were higher. These leaves were completely symptomless (Fig. 2).

In the roots from both the $\mathrm{RC}$ and nontransgenic plants either at 17 or $28 \mathrm{dpi}$, virus accumulated at a high level (Fig. 5A and B). No significant differences in virus levels were found between the RC and nontransgenic plants. These experiments were based on samples collected from total roots, and we also tested whether the virus titer was reduced in the newly emerging roots after recovery of leaf symptoms started. Samples from the old roots of virus-infected RC plants at 23 dpi and those from the newly emerging roots during the next 10 days were compared by ELISA, and no significant differences in virus titers were found between these two samples (data not shown). Thus, for virus-infected RC plants, the virus titers in the newly developed leaves were greatly reduced, but the newly emerging roots after recovery contained similar levels of virus as did the old roots before recovery.

Northern blot analysis (Fig. 5C) revealed that viral RNA accumulations in leaves at different positions and in the roots from the RC and nontransgenic plants at 28 dpi were consistent with the data from tissue imprinting and ELISA. BNYVVgenomic RNAs were not detected in recovered leaves of the RC plants (Fig. 5C, lanes 15 to 17). Their absence from recovered leaves was confirmed by RT-PCR (data not shown). In contrast, BNYVV RNAs accumulated in roots of the RC plants (Fig. 5C, lanes 9 to 11) to almost the same levels as in roots of the nontransgenic plants (Fig. 5C, lanes 3 and 4).

\section{Difference of mRNA degradation}

in leaves and roots of transgene-silenced plants.

To examine the differences of resistance in leaves and roots of the HR plants that were induced by RNA silencing, we com-

A

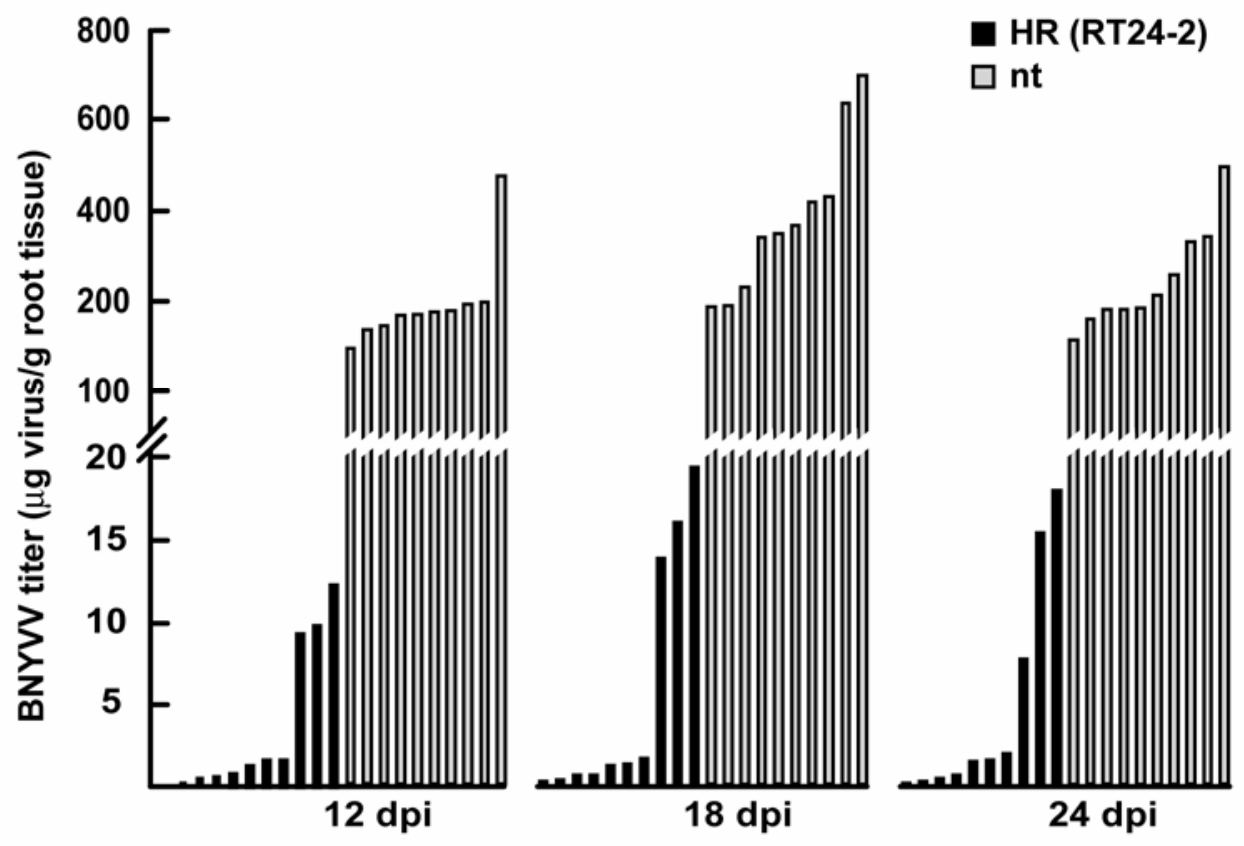

B

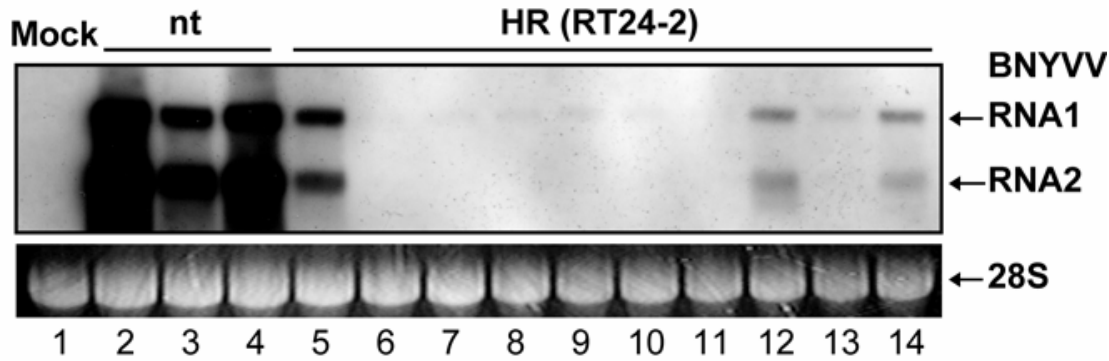

Fig. 4. Virus accumulation in roots of Beet necrotic yellow vein virus (BNYVV) 54-kDa readthrough domain-open reading frame (RTD-ORF) transgenic highly resistant (HR) or nontransgenic (nt) Nicotiana benthamiana plants inoculated with viruliferous zoospores of Polymyxa betae. A, Enzyme-linked immunosorbent assay (ELISA) of roots of HR plants (RT24-2, black bars) or nt plants (gray bars) at 12, 18, and 24 days postinoculation (dpi). Each bar corresponds to an individual plant. B, Northern blot analysis of total RNA extracted from roots of nt or HR plants at 20 dpi or from roots of a nonviruliferous $P$. betae-inoculated nt plant (mock). Each lane shows an individual plant. Total RNA was loaded per lane, and digoxigenin-labeled DNA probes specific for BNYVV RNA1 and RNA2 were used for hybridization. The two BNYVV genomic bands are shown (top). Ethidium bromide-stained 28S rRNA is shown as loading control (bottom). 

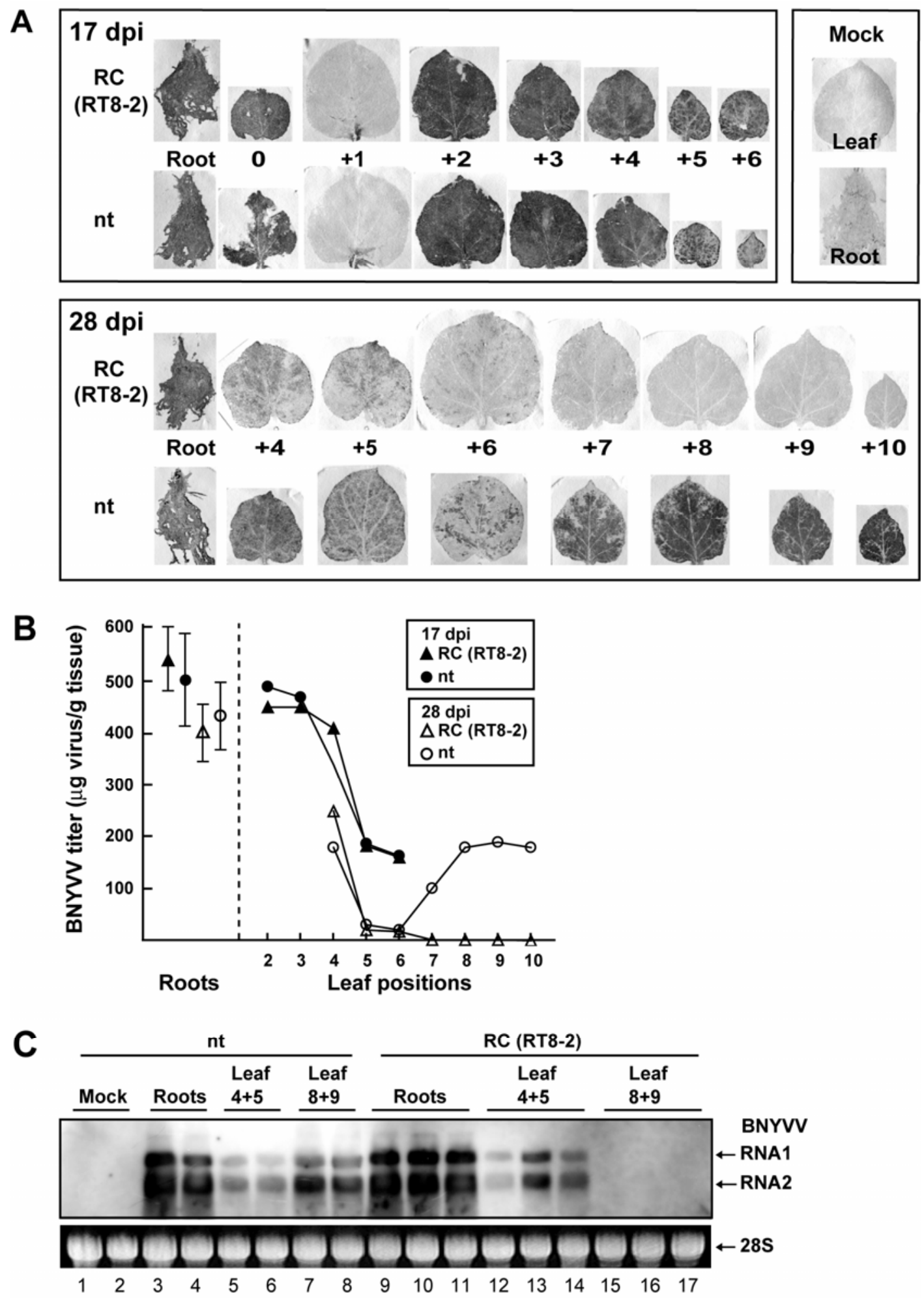

Fig. 5. Analysis of virus accumulation in leaves at different positions and in roots of Beet necrotic yellow vein virus (BNYVV) 54-kDa readthrough domainopen reading frame (RTD-ORF) transgenic recovery (RC) or nontransgenic (nt) Nicotiana benthamiana plants infected with BNYVV-O11. Plants were inoculated by rub-inoculation with BNYVV on two fully expanded leaves (position 0). At 17 days postinoculation (dpi), samples for tissue imprinting and enzyme-linked immunosorbent assay (ELISA) were collected from the inoculated leaves and leaves at positions +1 to +6 above the inoculated leaf and from the roots. At $28 \mathrm{dpi}$, samples were collected from leaves at positions +4 to +10 and from the roots. A, Tissue imprinting assay in RC (RT8-2) and nt plants. Leaves and roots of a mock-inoculated nt plant are also shown. Numbers indicate leaf positions. Results are representative of at least three independent experiments. B, ELISA on leaf and root extracts of RC (RT8-2) and nt plants. The values (microgram of virus per gram of tissue) are the mean from two samples from each leaf of one plant, and those in roots are the mean from each root of six plants. Results on leaf positions are representative of three independent experiments. C, Northern blot analysis of total RNA extracted from leaves and roots of RC (RT8-2) and nt plants at 28 dpi. Samples were collected from each of two nt plants or three RC plants; samples from leaves at positions +4 and +5 and those from leaves at positions +8 and +9 were mixed. Leaf and root samples (lanes 1 and 2, respectively) from a mock-inoculated nt plant are included. Total RNA was hybridized with digoxigenin-labeled DNA probes specific for RNA1 and RNA2 of BNYVV. The two BNYVV genomic bands are shown. Ethidium bromide-stained 28S rRNA is shown as loading control (bottom panel). 
pared the amounts of transgene mRNA and transgene-derived siRNAs in leaves and roots of the 54-kDa RTD-ORF-silenced plants (RT24-2). As shown previously, leaves in the silenced plants contained only a low level of transgene mRNA, but roots of the same plants contained much higher levels of mRNA (Fig. 6A, lanes 3 and 4). In contrast, transgene-derived siRNAs accumulated at higher levels in leaves but at lower levels in roots (Fig. 6A, lanes 3 and 4). In the 54-kDa RTD-ORFexpressing plants (RT8-2) used as a control, high levels of mRNA were detected in both the leaves and roots, and transgene-derived siRNAs were not detected (Fig. 6A, lanes 1 and 2). Thus, the levels of transgene mRNAs and siRNAs in the silenced plants are different in leaves and in roots.

To examine differences in silencing in leaves and roots outside of the context of a viral sequence, we used sGFP-silenced plants. A sGFP gene was transformed into $N$. benthamiana by the same methods used for transformation with the $54-\mathrm{kDa}$ RTD-ORF sequence. Of 16 sGFP-transgenic lines, two lines were selected, a line (G5) consistently expressing sGFP in all the aerial parts and roots of the plants and a line (G10) that was strongly silenced. Leaves of plants of the line G10, in which the sGFP fluorescence was undetectable under the fluorescence microscope, were infiltrated with an A. tumefaciens strain carrying the sGFP gene. After four to five days, little or no fluorescence was detected in infiltrated regions of the leaf. In contrast, the sGFP fluorescence was observed in infiltrated regions of nontransgenic control plants. In the sGFP-silenced plants (G10), only very low levels of sGFP mRNA were detected in the leaves (Fig. 6B, lane 4), whereas in roots, sGFP mRNA was readily detected although, it was not highly abundant (Fig. 6B, lane 3). In contrast, sGFP transgene-derived siRNAs accumulated to high levels in the leaves but to lower levels in roots (Fig. 6B, lanes 3 and 4). In the sGFP-expressing plants (G5), high levels of sGFP mRNA were present in both leaves and roots (Fig. 6B, lanes 1 and 2). These data are consistent with the results obtained in the 54-kDa RTD-ORFsilenced plants (HR plants) described above, indicating that the extent of degradation of transgene mRNA in silenced plants is lower in roots than in leaves.

\section{Difference of viral RNA degradation in leaves and roots of BNYVV-infected plants.}

To determine if the differences in amounts of viral RNAs in leaves and roots are due to differences in the effectiveness of virus-induced RNA silencing in the two types of tissue, we compared accumulation levels of viral-derived siRNAs in leaves and roots of nontransgenic plants. At 13 dpi, viral RNA accumulated to higher levels in roots than in leaves, whereas virus-derived siRNAs accumulated to higher in leaves than in roots (Fig. 6C, lanes 1 and 2). At $20 \mathrm{dpi}$, when symptoms in newly developing leaves became milder, viral RNA decreased greatly in leaves and siRNAs were present at low levels (Fig. 6C, lane 4). At 29 dpi, when severe symptoms reappeared, viral RNA and siRNAs reaccumulated to high levels in leaves (Fig. 6C, lane 6). At either 20 or $29 \mathrm{dpi}$, in roots, viral RNAs accumulated to high levels, whereas siRNAs accumulated to only low levels (Fig. 6C, lanes 3 and 5). These data suggest that the extent of degradation of viral RNAs is lower in roots than in leaves.

\section{DISCUSSION}

We find here that transgenic $N$. benthamiana plants transformed with the 54-kDa RTD ORF of BNYVV displayed HR and $\mathrm{RC}$ phenotypes at high frequency. The HR plants are immune to foliar rub-inoculation with BNYVV. The RC plants are initially infected systemically, but subsequently, they produced new leaves with progressively fewer symptoms and eventually produced virus-free leaves (Figs. 2 and 5) that were completely resistant to superinfection. Molecular analyses (Fig. 3) revealed that resistance in HR plants is mediated by RNA silencing and that recovery is mediated by virus infection-induced silencing of the transgene. These results are consistent with many previous observations (Dougherty et al. 1994: Goodwin et al. 1996; Guo and Garcia 1997; Lindbo et al.1993; Mueller et al. 1995; Ruiz et al. 1998; Smith et al. 1994), but this is the first report that the RTD-ORF gene, other than viral major genes such as $\mathrm{CP}$ and replicase, has been shown to have a potential to induce high resistance through the
A

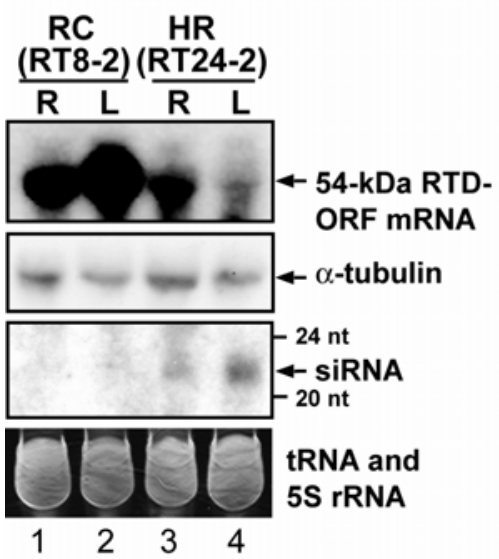

B

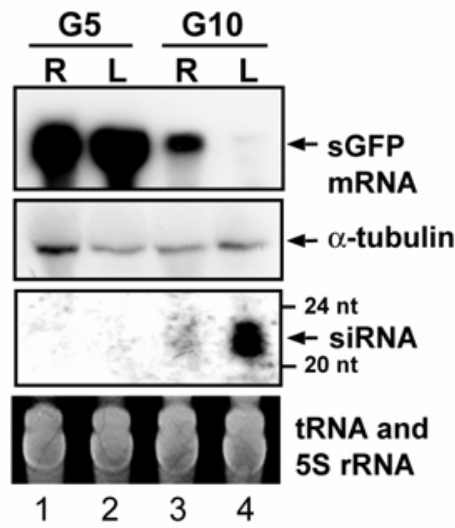

C

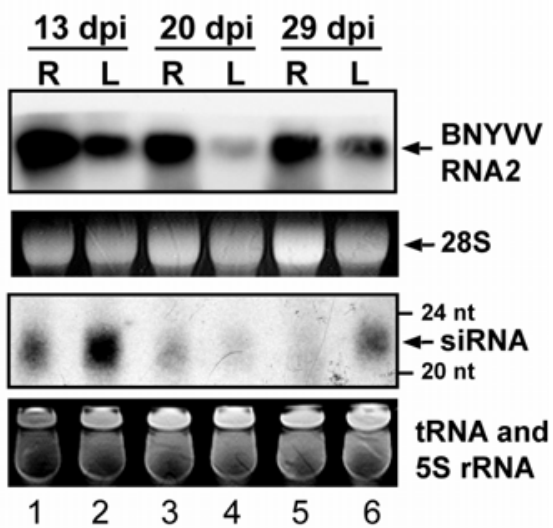

Fig. 6. Northern blot analysis in leaves and roots of transgene-silenced or Beet necrotic yellow vein virus (BNYVV)-infected nontransgenic (nt) Nicotiana benthamiana plants. A, BNYVV 54-kDa readthrough domain-open reading frame (RTD-ORF) transgenic plants, B, green fluorescent protein (sGFP)transgenic plants and C, BNYVV-infected nt plants. RNA samples were prepared from pooled leaves and roots of five plants. Total RNA was hybridized with a digoxigenin-labeled DNA probe specific for a 54-kDa RTD-ORF sequence or a sGFP sequence. For detection of short interfering RNAs (siRNAs), a ${ }^{32}$ Plabeled antisense RNA probe specific for a 54-kDa RTD-ORF or sGFP sequence was used for hybridization. The positions for 20- and 24-nucleotide DNA oligomers are indicated. As a loading control of transcripts of leaves and roots, the expression level of the alpha-tubulin gene is shown (second panel in A and B), and for siRNAs, ethidium bromide-stained tRNA and 5S rRNA are shown (bottom panel). A, Detection of transgene mRNA and siRNAs in leaves (L) and roots (R) of recovery (RC) (RT8-2) and highly resistant (HR) plants (RT24-2). B, Detection of transgene mRNA and siRNAs in leaves (L) and roots (R) of sGFP-expressing plants (G5) and sGFP-silenced plants (G10). C, Detection of viral RNA and siRNAs in leaves (L) and roots (R) of nt plants at 13, 20, and 29 days postinoculation (dpi). Ethidium bromide-stained 28S rRNA is shown as loading control (second panel). 
RNA silencing mechanism. The RTD-ORFs (and RTD-like ORF) following the $\mathrm{CP}$ gene are encoded by the genomes of the fungus-transmitted rod-shaped viruses (genus Benyvirus, Furovirus, Pomovirus, and Pecluvirus) (Hull 2002), and therefore, it is interesting to test whether the RTD-ORF transgene constructs for other viruses can induce similarly high resistance to virus.

On the other hand, $\mathrm{CP}$ gene transgenic plants did not show HR or RC phenotypes such as those seen in the 54-kDa RTDORF transgenic plants, regardless of the amount of CP transcript synthesized (data not shown). To date, there have been two reports in which sugar beet plants expressing the CP gene of BNYVV displayed resistance to virus infection (Kallerhoff et al. 1990; Mannerlof et al. 1996), although the resistance mechanism was not reported. It has also been reported that $N$. benthamiana transformed with the $\mathrm{CP}$ gene of Potato mop-top virus (PMTV, genus Pomovirus) showed strong resistance to the virus, irrespective of the amount of transcript RNA or CP detected (Barker et al. 1998; Reavy et al. 1995). This resistance seems likely to result from a complex mechanism in which both protein- and RNA-mediated resistance are involved (Barker et al. 1998; Germundsson et al. 2002). These differences may be due to the different virus species or different gene constructions used.

In nature, BNYVV is inoculated to roots of sugar beet plants by the soilborne fungus $P$. betae (Tamada 1999), and therefore, it is important to examine whether transgenic plants show resistance to fungus inoculation to roots as well as to foliar rubinoculation. Two soilborne viruses, Tobacco rattle virus (TRV) and PMTV, have been so far tested using viruliferous vectors. Transgenic plants expressing the TRV CP gene were resistant to foliar rub-inoculation with TRV but susceptible to rootinoculation by viruliferous nematodes (Ploeg et al. 1993). In contrast, PMTV CP transgenic plants showed high resistance to both the foliar rub-inoculation and fungus-inoculation to roots (Reavy et al. 1995). Thus, it is poorly understood whether pathogen-mediated resistance functions similarly in roots and leaves, although several viruses infect the root systems of many commercially important crop species (Hull 2002; Verchot-Lubicz 2003). Therefore, in this study, we compared the efficiency of RNA silencing-mediated resistance in leaves and roots, using different types of the 54-kDa RTDORF transgenic plants in which virus- or transgene-induced RNA silencing operates.

First, fungal inoculation tests revealed that viruliferous zoospores of $P$. betae were able to inoculate the virus to roots of the HR plants that are immune to foliar rub-inoculation, but the virus multiplication, movement, or both was greatly limited (Fig. 4). Clearly, the low virus content of the HR plants occurs as a consequence of transgene-induced RNA silencing in roots. In silenced plants, however, levels of transgene mRNA were higher in roots than in leaves (Fig. 6A and B), and correspondingly, levels of transgene-derived siRNAs were lower in roots than in leaves (Fig. 6A and B). These data suggest that the extent of degradation of transgene mRNA in the silenced plants is lower in roots than in leaves. Therefore, it is likely that the difference of degradation reflects a reduction of virus resistance in roots. However, it is also possible that the decline of resistance in roots may be due to some aspect of virus-vector interaction. For example, viruliferous zoospores of $P$. betae can infect a larger number of root cells and introduce many more virus particles into a cell than with rub-inoculation on leaves. On the other hand, it is worth noting that for PMTV, another fungus-transmitted virus, resistance in N. benthamiana transformed with the PMTV CP gene was more effective in mechanically inoculated leaves than in roots of plants grown in soil containing viruliferous vector Spongospora sub- terranea (Germundsson et al. 2002). These data are thus similar to our results, although the gene that induces resistance is different.

Second, we compared accumulation levels of viral RNAs and viral-derived siRNAs in leaves and roots of nontransgenic $N$. benthamiana plants. There are three phases in symptom development (Fig. 2) and virus accumulation (Fig. 5) in systemically infected plants following foliar rub-inoculation. The first phase is a high level of virus accumulation during the first two weeks after inoculation. The second phase is virus reduction in newly developing leaves during the next week. In the third phase, virus accumulation in leaves emerging at three weeks after inoculation increases again. In this last stage, the symptoms were more pronounced, showing mosaic and leaf distortions that are different from the initial leaf-curling symptoms. Thus, natural recovery from BNYVV infection occurs in nontransgenic $N$. benthamiana, but this is only transient. The accumulation of virus-derived siRNAs in infected leaves in the first phase (Fig. 6C) suggests that this natural recovery is induced by RNA silencing via sequence-specific degradation of BNYVV. Compared with a reduction on accumulation of viral RNAs in leaves in the second phase, viral RNA accumulation in the roots remained at high levels into the third phase. In addition, siRNAs were abundant in the leaves but were present at lower levels in the roots (Fig. 6C). These data suggest that the degree of RNA silencing-mediated degradation of viral RNAs is lower in roots than in leaves.

Third, for transgenic RC plants inoculated with BNYVV, the kinetics of virus accumulation in the first and second phases were the same as in nontransgenic plants but were very different in the third phase, in which a drastic decline of virus amounts in the RC plants occurred (Fig. 5). This indicates that the timing of induction (initiation) of recovery in transgenic and nontransgenic plants is similar. In transgenic plants, the presence of the transgene influences the efficiency of propagation and maintenance of the subsequent silencing signal through the plant (Ruiz et al. 1998). Once triggered, the silencing signal is able to move systemically in plants expressing the virus transgene, and the spread of the systemic signal results in recovery from virus infection (Voinnet et al. 1998). Interestingly, in the third phase in RC plants, a significant reduction of virus concentration was not found in newly developed roots, in contrast to the drastic reduction of virus levels in leaves. One possibility is that systemic spread of the silencing signal from shoots to roots is incomplete or partial. Indeed, it has been reported that the RNA silencing is not effective in the apical meristem in both roots and shoots of silenced plants (Voinnet et al. 1998), presumably because the silencing signal cannot reach those regions. Another possibility is that silencing capacity (activity) in roots is lower than in leaves, as discussed above.

In conclusion, we have provided novel evidence that the RNA silencing mechanism is less effective in roots than in leaves. It is possible that the high steady levels of viral RNA accumulation in roots of nontransgenic and transgenic $\mathrm{RC}$ plants are due to ineffectiveness of virus-induced RNA silencing in these tissues. Our success in infecting roots of transgenic HR plants by the viruliferous fungus could also be explained by a reduced activity of transgene-induced RNA silencing. In both virus- and transgene-induced RNA silencing, the most remarkable feature is a lower accumulation of siRNAs in roots. It is generally accepted that siRNAs are generated from the precursor dsRNA by the action of an RNase III-like enzyme named Dicer (Bernstein et al. 2001; Tang et al. 2003). Virus- and transgene-induced RNA silencing pathways differ mainly in the generation of dsRNAs. In virusinduced RNA silencing, double-stranded replicative RNA 
forms of RNA viruses are synthesized by a viral-encoded RdRP, whereas transgene-derived dsRNAs are likely generated by a plant-encoded RdRP from aberrant transcripts (Dalmay et al. 2000). One possible explanation for the low levels of siRNAs in the roots is that the activity of Dicer-related enzyme or its downstream pathway (such as RISC) may be intrinsically low in the root system. It is also possible that the stability of siRNAs may be reduced in roots, that the extent of systemic spread of the silencing signal in roots is more limited, or both. Indeed, it has been recently shown that when RNA silencing was induced in roots by Agrobacterium rhizogenes-mediated transformation, the silencing signal did not spread systemically to nontransformed roots and only inefficiently to the nontransgenic shoots (Kumagai and Kouchi 2003; Limpens et al. 2004). Thus, the RNA silencing pathway in the root system may be fundamentally different than in the aerial parts of the plant and further work is needed to clarify these differences.

\section{MATERIALS AND METHODS}

\section{Vector construction and plant transformation.}

Three plasmids, pBI-CP, pBI-RTD, and pBI-sGFP, containing a 21-kDa CP gene, a 54-kDa RTD-ORF sequence, and a sGFP gene, respectively, were constructed as follows (Fig. 1A). BNYVV-O11 (originated from Obihiro, Japan) and the sGFP expression vector p35S-sGFP(S65T) (Chiu et al. 1996) were used in this study. cDNA fragments containing the CPencoding region (nt 144 to 711) or the 54-kDa RTD ORF (nt 712 to 2,217) were amplified by PCR. The primers were as follows: for the $\mathrm{CP}$ gene amplification, a forward primer, 5'GTGGATCCATGTCGAGTGAAGGTAGATATA-3', and a reverse primer, 5'-GTGAGCTCTATTGTCCGGGTGGACTG-3'; for amplification of the 54-kDa RTD ORF, a forward primer, 5'-CCGGATCCATGCAATTAGCTGCTGCTC-3', and a reverse primer, 5'-CCGAGCTCATCCGGCGGGAGCGGA-3'. Forward and reverse primers were designed to contain BamHI and SacI restriction sites (bold italic letters), respectively, required for cloning and construction of the plant transformation vectors (Fig. 1A). The translational start codon (ATG) is underlined and the suppressible termination codon (TAG) separating the $\mathrm{CP}$ and $54-\mathrm{kDa}$ ORFs was replaced by a start codon (ATG) (Fig. 1A). The PCR-amplified fragments were cloned into the pZErO-2 cloning vector (Invitrogen, San Diego, CA, U.S.A.) according the manufacturer's instructions. The DNA fragment of the CP gene or the 54-kDa RTD ORF was inserted between the $35 \mathrm{~S} \mathrm{CaMV}$ promoter and NOS terminator sequences of the binary vector pBI121 (Clontech Labs, Palo Alto, CA, U.S.A.), after the $\beta$-glucuronidase gene had been removed. For construction of the sGFP binary vector, the cassette from p35SsGFP(S65T) was digested with HindIII and EcoRI and ligated into the binary vector $\mathrm{pBI} 121$.

Each of these pBI121-derived constructs (pBI-CP, pBI-RTD, and pBI-sGFP) was transformed into A. tumefaciens LBA4404 (Hoekema et al. 1983) by electroporation, and $N$. benthamiana plants were transformed by the leaf disk method as described previously (Topping 1998). Selection and further propagation of the transgenic lines were carried out on Murashige-Skoogbased medium containing kanamycin $(100 \mu \mathrm{g} / \mathrm{ml})$. Primary transformed seedlings $\left(\mathrm{T}_{0}\right)$ were transplanted to soil and were grown in a glasshouse. The presence of inserted genes in transgenic plants was confirmed by PCR of total genomic DNA, using primers specific for the CaMV $35 \mathrm{~S}$ promoter and NOS terminator. The plants were self-fertilized, and seeds $\left(T_{1}\right)$ from each transgenic plant were collected and germinated in plastic pots containing quartz sand. Kanamycin-resistant seedlings were transplanted into special test tubes ( $24 \mathrm{~mm}$ wide and 120 $\mathrm{mm}$ long with a drainage hole) filled with quartz sand and were grown in a growth cabinet at $24^{\circ} \mathrm{C}$ with a 16 -h light and 8-h dark cycle (Tamada and Kusume 1991).

\section{DNA and RNA blot analyses.}

Genomic DNA was isolated from leaf tissue as described by Murray and Thompson (1980). Total DNA (10 to $20 \mu \mathrm{g}$ ) was digested with a restriction enzyme (XbaI or HindIII), was separated in a $0.7 \%$ agarose gel, and was transferred to Hybond- $\mathrm{N}^{+}$ membranes (Amersham Biosciences, Piscataway, NJ, U.S.A.). The blot was hybridized with a digoxigenin (DIG)-labeled DNA probe specific to the 54-kDa RTD-ORF sequence (Fig. 1A) by using a PCR DIG probe synthesis kit (Roche, Mannheim, Germany).

Total RNA was extracted from leaf or root tissue by the acid guanidinium thiocyanate-phenol-chloroform method (Chomczynski and Sacchi 1987). RNA samples (15 to $20 \mu \mathrm{g}$ ) were separated on a $1.5 \%$ agarose gel containing $3 \%$ formaldehyde and were transferred to Hybond $-\mathrm{N}^{+}$membranes. The blot was hybridized with a DIG-labeled DNA probe specific for the 54-kDa RTD-ORF sequence (Fig. 1A) or sGFP gene sequence. For detection of viral RNAs, a mixture of DIGlabeled DNA probes specific for the BNYVV RNA1 (nt 5,815 to 6,531) and RNA2 (nt 144 to 711) sequences was used (Saito et al. 1996). Equal loading was verified by visualization of ethidium bromide-stained 28S rRNA. To normalize the level of transcript accumulation in leaves and roots, blots also were hybridized with a DIG probe obtained from the $N$. benthamiana alpha-tubulin gene.

The siRNAs were extracted essentially as described by Hamilton and Baulcombe (1999). High molecular weight RNAs were removed from total RNAs by centrifugation in the presence of $5 \%$ polyethylene glycol 8000 and $0.5 \mathrm{M}$ $\mathrm{NaCl}$. Low molecular weight RNAs were cleaned up with Qiagen columns (Qiagen RNA/DNA mini kit; Qiagen, Hilden, Germany). The RNAs (40 to $50 \mu \mathrm{g}$ ) were separated on a $15 \%$ polyacrylamide $7 \mathrm{M}$ urea gel, were transferred to the HybondNX membranes (Amersham-Biosciences), and were hybridized with the ${ }^{32} \mathrm{P}$-labeled sense or antisense RNA probe corresponding to the region of 54-kDa RTD-ORF sequence (Fig. 1A) or sGFP gene. These RNA probes were generated by in vitro transcription using SP6 or T7 RNA polymerase (Promega, Madison, WI, U.S.A.). Equal loading was verified by visualization of ethidium bromide-stained tRNAs and 5S rRNA.

\section{Virus inoculations.}

For foliar rub-inoculation, BNYVV-O11-infected N. benthamiana leaves were ground in $0.1 \mathrm{M}$ phosphate buffer, $\mathrm{pH}$ 7.4, containing $0.5 \%$ 2-mercaptoethanol. The sap was rubbed onto Carborundum-dusted leaves of $N$. benthamiana plants.

Fungus inoculation was conducted as described by Tamada and Kusume (1991). Viruliferous zoospore suspension derived from fungus-infected sugar beet roots was obtained by collecting waste drained from the bottom hole of the test tubes into which nutrient solution had been poured; this inoculum was added to test tubes in which 4-week-old N. benthamiana seedlings were grown.

\section{Virus detection}

\section{by ELISA, tissue imprinting assay, and RT-PCR.}

ELISA of infected plants was conducted as described by Tamada and Abe (1989). Leaf or root tissue was homogenized in 1:20 (wt/vol) extraction buffer $(0.02 \mathrm{M}$ potassium phosphate buffer, $\mathrm{pH} 7.4,0.15 \mathrm{M} \mathrm{NaCl}, 0.05 \%$ Tween 20 , and $2 \%$ polyvinylpyrrolidone [PVP]). Further 10-fold dilutions of each extract were also prepared in this extraction buffer. Samples were added to the microplates (Nunc-Immuno plate; Nunc, Roskilde, Den- 
mark) coated with rabbit anti-BNYVV polyclonal immunoglobulin (IgG). The same IgG that was conjugated with alkaline phosphatase was used for detection with $p$-nitrophenyl phosphate as substrate. Absorbance values at $405 \mathrm{~nm}$ were recorded with a micro plate reader MPR-A4 (Toyo Soda, Tokyo). The virus concentrations in tissue extracts were calculated based on a standard curve of absorbance values against known concentrations of purified virus.

Tissue imprinting assay of infected plants was conducted as described by Suehiro and associates (2004). Leaf or root samples were sandwiched between two filter papers (Advantec; Toyo Soda) and pressed with a wooden hammer. Resident green color was removed from the filter by rinsing in $2 \%$ Triton $\mathrm{X}-100$. The blotted filter papers were blocked for $30 \mathrm{~min}$ in blocking solution $(20 \mathrm{mM}$ Tris- $\mathrm{HCl}, \mathrm{pH} 7.5,500 \mathrm{mM} \mathrm{NaCl}$ Tris-buffered saline [TBS], $1 \%$ bovine serum albumin [BSA]) and then were incubated overnight with rabbit anti-BNYVV polyclonal $\mathrm{IgG}$ in antibody dilution buffer (TBS, $2 \% \mathrm{PVP}$, and $1 \%$ BSA). After washing with washing buffer (TBS and $0.05 \%$ Tween 20), the papers were incubated for $2 \mathrm{~h}$ with a goat antirabbit IgG conjugated to alkaline phosphatase. Colorimetric detection of the tissue print was performed by incubation with nitro blue tetrazolium chloride and 5-bromo-4-chloro-3-indolyl phosphate.

Virus detection by RT-PCR was conducted as described by Miyanishi and associates (1999), except that total RNA from roots was extracted by using Qiazol Lysis Reagent (Qiagen). The following primers were used: for detection of RNA1, the forward primer 1N (5'-GTCAGAGCACATATGTCT-3', nt $5,815$ to 5,832$)$ and the reverse primer $1 \mathrm{~B}\left(5^{\prime}\right.$-CTTATACTA CTCACAAGGATCCAACG-3', complementary to nt 6,506 to $6,531)$ and for detection of RNA2, the forward primer $2 \mathrm{~N}\left(5^{\prime}-\right.$ CAGAACATATTTCATATGGTGCTTG-3', nt 3,609 to 3,633) and the reverse primer $2 \mathrm{~B}\left(5^{\prime}\right.$-CCATCCCCATACGGATCC TACCAC-3', complementary to nt 4,026 to 4,049 ).

\section{Detection of GFP fluorescence and agroinfiltration.}

The sGFP fluorescence of sGFP-transgenic plants was observed with a fluorescence microscope (Zeiss Axioskop, Germany) equipped with a 10 filter (450 to $490 \mathrm{~nm}$ excitation filter, $510 \mathrm{~nm}$ dichroic mirror, 515 to $565 \mathrm{~nm}$ emission filter). For agroinfiltration, A. tumefaciens C58 carrying a sGFP binary vector described above was cultured and used to infiltrate leaves of 4-week-old $N$. benthamiana plants as described previously (English et al. 1997).

\section{ACKNOWLEDGMENTS}

We thank N. Suzuki, M. Nishiguchi, and S. Bouzoubaa for technical advice and helpful discussions. We also thank K. Richards for critically reading the manuscript. Financial support from Hokkaido Sugarbeet Association and from Yomogi Inc. is also acknowledged.

\section{LITERATURE CITED}

Barker, H., Reavy, B., McGeachy, K. D., and Dawson, S. 1998. Transformation of Nicotiana benthamiana with the potato mop-top virus coat protein gene produces a novel resistance phenotype mediated by the coat protein. Mol. Plant-Microbe Interact. 11:626-633.

Baulcombe, D. C. 1996. Mechanism of pathogen-derived resistance to viruses in transgenic plants. Plant Cell 8:1833-1844.

Bernstein, E., Caudy, A. A., Hammond, S. M., and Hannon, G. J. 2001. Role for a bidentate ribonuclease in the initiation step of RNA interference. Nature 409:363-366.

Bouzoubaa, S., Ziegler, V., Beck, D., Guilley, H., and Richards, K. 1986. Nucleotide sequence of beet necrotic yellow vein virus RNA-2. J. Gen. Virol. 67:1689-1700.

Chiu, W., Niwa, Y., Zeng, W., Hirano, T., Kobayashi, H., and Sheen, J. 1996. Engineered GFP as a vital reporter in plants. Curr. Biol. 6:325-330.

Chomczynski, P., and Sacchi, N. 1987. Single-step method of RNA isola- tion by acid guanidinium thiocyanate-phenol-chloroform extraction. Anal. Biochem. 162:156-159.

Dalmay, T., Hamilton, A., Rudd, S., Angell, S., and Baulcombe, D. C. 2000. An RNA-dependent RNA polymerase gene in Arabidopsis is required for post-transcriptional gene silencing mediated by a transgene but not by a virus. Cell 101:543-553.

Dougherty, W. G., Lindbo, J. A., Smith, H. A., Parks, T. D., Swaney, S., and Proebsting, W. M. 1994. RNA-mediated virus resistance in transgenic plants: Exploitation of a cellular pathway possibly involved in RNA degradation. Mol. Plant-Microbe Interact. 7:544-552.

Dunoyer, P., Pfeffer, S., Fritsch, C., Hemmer, O., Voinnet, O., and Richards, K. E. 2002. Identification, subcellular localization and some properties of a cysteine-rich suppressor of gene silencing encoded by peanut clump virus. Plant J. 29:555-567.

Elbashir, S. M., Lendeckel, W., and Tuschl, T. 2001. RNA interference is mediated by 21- and 22-nucleotide RNAs. Genes Dev. 15:188-200.

English, J. J., Davenport, G. F., Elmayan, T., Vaucheret, H., and Baulcombe, D. C. 1997. Requirement of sense transcriptional for homology-dependent virus and trans-inactivation. Plant J. 12:597-603.

Germundsson, A., Sandgren, M., Barker, H., Savenkov, E. I., and Valkonen, J. P. 2002. Initial infection of roots and leaves reveals different resistance phenotypes associated with coat protein gene-mediated resistance to Potato mop-top virus. J. Gen. Virol. 83:1201-1209.

Gilmer, D., Bouzoubaa, S., Hehn, A., Guilley, H., Richards, K., and Jonard, D. 1992. Efficient cell-to-cell movement of Beet necrotic yellow vein virus requires $3^{\prime}$ proximal genes located on RNA2. Virology 189:40-47.

Goodwin, J., Chapman, K., Swaney, S., Parks, T. D., Wernsman, E. A., and Dougherty, W. G. 1996. Genetic and biochemical dissection of transgenic RNA-mediated virus resistance. Plant Cell 8:95-105.

Guo, H. S., and Garcia, J. A. 1997. Delayed resistance to plum pox potyvirus mediated by a mutated RNA replicase gene: Involvement of a gene silencing mechanism. Mol. Plant-Microbe Interact. 10:160-170.

Haeberle, A. M., Stussi-Garaud, C., Schmitt, C., Garaud, J. C., Richards, K. E., Guilley, H., and Jonard, G. 1994. Detection by immunogold labeling of P75 readthrough protein near an extremity of beet necrotic yellow vein virus particles. Arch. Virol. 134:195-203.

Hamilton, A. J., and Baulcombe, D. C. 1999. A species of small antisense RNA in posttranscriptional gene silencing in plants. Science 286:950952.

Hammond, S. M., Bernstein, E., Beach, D., and Hannon, G. J. 2000. An RNA-directed nuclease mediates post-transcriptional gene silencing in Drosophila cells. Nature 404:293-296.

Herzog, E., Guilley, H., and Fritsch, C. 1995. Translation of the second gene of peanut clump virus RNA 2 occurs by leaky scanning in vitro. Virology 208:215-225.

Hoekema, A., Hirsch, P. R., Hooykaas, P. J. J., and Schilperoort, R. A. 1983. A binary plant vector strategy based on separation of vir- and Tregion of the Agrobacterium tumefaciens Ti-plasmid. Nature 303:179180.

Hull, R. 2002. Matthews Plant Virology. 4th ed. Academic Press, San Diego, CA, U.S.A.

Kallerhoff, J., Perez, P., Bouzoubaa, S., Tahar, S. B., and Perret, J. 1990. Beet necrotic yellow vein virus coat protein-mediated protection in sugar beet (Beta vulgaris L.) protoplasts. Plant Cell Rep. 9:224-228.

Kumagai, H., and Kouchi, H. 2003. Gene silencing by expression of hairpin RNA in Lotus japonicus roots and root nodules. Mol. Plant-Microbe Interact. 16:663-668.

Limpens, E., Ramos, J., Franken, C., Raz, V., Compaan, B., Franssen, H., Bisseling, T., and Geurts, R. 2004. RNA interference in Agrobacterium rhizogenes-transformed roots of Arabidopsis and Medicago truncatula. J. Exp. Bot. 55:983-992.

Lindbo, J. A., Silva-Rosales, L., Proebsting, W. M., and Dougherty, W. G. 1993. Induction of a highly specific antiviral state in transgenic plants: Implications for regulation of gene expression and virus resistance. Plant Cell 5:1749-1759.

Llave, C., Kasschau, K. D., Rector, M. A., and Carrington, J. C. 2002. Endogenous and silencing-associated small RNAs in plants. Plant Cell 14:1605-1619.

Mannerlof, M., Lennerfors, B.-L., and Tenning, P. 1996. Reduced titer of BNYVV in transgenic sugar beets expressing the BNYVV coat protein. Euphytica 90:293-299.

Matzke, M., Matzke, A. J., and Kooter, J. M. 2001. RNA: Guiding gene silencing. Science 293:1080-1083.

Miyanishi, M., Kusume, T., Saito, M., and Tamada, T. 1999. Evidence for three groups of sequence variants of beet necrotic yellow vein virus RNA 5. Arch. Virol. 144:879-892.

Mlotshwa, S., Voinnet, O., Mette, M. F., Matzke, M., Vaucheret, H., Ding, S. W., Pruss, G., and Vance, V. B. 2002. RNA silencing and the mobile silencing signal. Plant Cell 14:S289-S301. 
Mueller, E., Gilbert, J. E., Davenport, G., Brigneti, G., and Baulcombe, D. C. 1995. Homology-dependent resistance: Transgenic virus resistance in plants related to homology-dependent gene silencing. Plant $\mathrm{J}$. 7:1001-1013.

Murray, M. G., and Thompson, W. F. 1980. Rapid isolation of high molecular weight plant DNA. Nucleic Acids Res. 8:4321-4325.

Palauqui, J. C., Elmayan T., Pollien, J. M., and Vaucheret H. 1997. Systemic acquired silencing: Transgene-specific post-transcriptional silencing is transmitted by grafting from silenced stocks to non-silenced scions. EMBO (Eur. Mol. Biol. Organ.) J. 16:4738-4745.

Ploeg, A. T., Mathis, A., Bol, J. F., Brown, D. J. F., and Robinson, D. J. 1993. Susceptibility of transgenic tobacco plants expressing tobacco rattle virus coat protein to nematode-transmitted and mechanically inoculated tobacco rattle virus. J. Gen. Virol. 74:2709-2715.

Reavy, B., Arif, M., Kashiwazaki, S., Webster, K. D., and Barker, H. 1995. Immunity to Potato mop-top virus in Nicotiana benthamiana plants expressing the coat protein gene is effective against fungal inoculation of the virus. Mol. Plant-Microbe Interact. 8:286-291.

Ruiz, M. T., Voinnet, O., and Baulcombe, D. C. 1998. Initiation and maintenance of virus-induced gene silencing. Plant Cell. 10:937-946.

Saito, M., Kiguchi, T., Kusume, T., and Tamada, T. 1996. Complete nucleotide sequence of the Japanese isolate $\mathrm{S}$ of beet necrotic yellow vein virus RNA and comparison with European isolates. Arch. Virol. 141:2163-2175.

Schmitt, C., Balmori, E., Jonard, G., Richards, K. E., and Guilley, H. 1992. In vitro mutagenesis of biologically active transcripts of beet necrotic yellow vein virus RNA 2: Evidence that a domain of the $75-\mathrm{kDa}$ readthrough protein is important for efficient virus assembly. Proc. Natl. Acad. Sci. U.S.A 89:5715-5719.

Smith, H. A., Swaney, S. L., Parks, T. D., Wernsman, E. A., and Dougherty, W. G. 1994. Transgenic plant virus resistance mediated by untranslatable sense RNAs: Expression, regulation, and fate of nonessential RNAs. Plant Cell 6:1441-1453.

Suehiro, N., Natsuaki, T., Watanabe, T., and Okuda, S. 2004. An important determinant of the ability of Turnip mosaic virus to infect Brassica spp. and/or Raphanus sativus is in its P3 protein. J. Gen. Virol. 85:20872098.

Tamada, T. 1999. Benyvirus. Pages 154-160 in: Encyclopedia of Virology. 2nd ed. R. G. Webster and A. Granoff, eds. Academic Press, London.

Tamada, T., and Abe, H. 1989. Evidence that beet necrotic yellow vein virus RNA 4 is essential for efficient transmission by the fungus Polymyxa betae. J. Gen. Virol. 70:3391-3398.

Tamada, T., and Kusume, T. 1991. Evidence that the $75 \mathrm{~K}$ readthrough protein of beet necrotic yellow vein virus RNA-2 is essential for transmission by the fungus Polymyxa betae. J. Gen. Virol. 72:14971504.

Tamada, T., Schmitt, C., Saito, M., Guilley, H., Richards, K., and Jonard, G. 1996. High resolution analysis of the readthrough domain of beet necrotic yellow vein virus readthrough protein: A KTER motif is important for efficient transmission of the virus by Polymyxa betae. J. Gen. Virol. 77:1359-1367.

Tang, G., Reinhart, B. J., Bartel, D. P., and Zamore, P. D. 2003. A biochemical framework for RNA silencing in plants. Genes Dev. 17:49-63.

Topping, J. F. 1998. Tobacco transformation. Pages 365-372 in: Methods in Molecular Biology Vol. 20: Plant Virology. G. D. Foster, ed. Humana Press. Totowa, NJ, U.S.A.

Vance, V., and Vaucheret, H. 2001. RNA silencing in plants-Defense and counterdefense. Science 292:2277-2280.

Verchot-Lubicz, L. 2003. Soilborne viruses: Advances in virus movement, virus induced gene silencing, and engineered resistance. Physiol. Mol. Plant Pathol. 62:55-63.

Voinnet, O. 2001. RNA silencing as a plant immune system against viruses. Trends Genet. 17:449-459.

Voinnet, O., Vain, P., Angell, S., and Baulcombe, D. C. 1998. Systemic spread of sequence-specific transgene RNA degradation in plants is initiated by localized introduction of ectopic promoterless DNA. Cell 95:177-187.

Waterhouse, P. M., Wang, M. B., and Lough, T. 2001. Gene silencing as an adaptive defence against viruses. Nature 411:834-842. 